Síntese - Rev. de Filosofia

v. 35 N. 112 (2008): 221-237

\title{
SOBRE O LIVRE JOGO DA IMAGINAÇÃO COM O ENTENDIMENTO NO J UÍZO DE GOSTO, EM KANT
}

\author{
Edgard J osé J orge Filho*
}

Resumo: Na Crítica da Faculdade do Juízo, Kant põe como fundamento do juízo de gosto o livre jogo da imaginação com o entendimento, que, ao produzir o acordo da liberdade da imaginação com a legalidade do entendimento, engendra o prazer sobre o qual se funda esse juízo. O objetivo deste estudo é procurar esclarecer em que consiste a liberdade desse jogo e acordo, considerando, inicialmente, que o princípio da faculdade de juízo reflexiva tem a forma do dever e que, portanto, a imaginação e o entendimento, atuantes nessa faculdade, estariam submetidos a deveres incondicionais, podendo-se atribuir-lhes a liberdade num sentido genuíno e não apenas num sentido psicológico, comparativo. Essa tese é sustentada face às objeções que apelam ao desinteresse do juízo de gosto e ao caráter psicológico da liberdade da imaginação.

Palavras-chave: Kant, juízo de gosto, livre jogo da imaginação com o entendimento, dever, liberdade.

Abstract: In the Critique of Judgment, Kant lays the foundation of the judgment of taste, namely the free play between imagination and understanding, which, in so far as it produces the accord of the freedom of the imagination with the lawfulness of the understanding, originates the pleasure on which this judgment is based. This study aims at throwing

\footnotetext{
* Professor no Departamento de Filosofia da PUC-Rio. Artigo submetido a avaliação no dia 24/1/2006 e aprovado para publicação no dia 22/10/2007.
} 
light on what the freedom of this play and accord consists of, considering first that the principle of the faculty of reflective judgment has the 'ought' form and, therefore, that the imagination and the understanding, which are active in that faculty, are under unconditional duties, so that freedom in its proper sense, not only in its psychological, comparative sense, may be ascribed to them. We maintain this thesis facing objections relating to the disinterestedness of the judgment of taste and to the psychological character of the freedom of the imagination.

Key-words: Kant, judgment of taste, free play of the imagination with the understanding, duty, freedom.

$\mathrm{N}$

a Crítica da Faculdade do Juízo, Kant põe como fundamento do juízo de gosto o livre jogo da imaginação com o entendimento, que, ao produzir o acordo da liberdade da imaginação com a legalidade do entendimento, engendra o prazer sobre o qual se funda esse juízo. ${ }^{1}$ O objetivo deste estudo é procurar esclarecer em que consiste a liberdade desse jogo e acordo, considerando, inicialmente, que o princípio da faculdade de juízo reflexiva tem a forma do dever e que, portanto, a imaginação e o entendimento, atuantes nessa faculdade, estariam subme tidos a deveres incondicionais, podendo-se atribuir-lhes a liberdade num sentido genuíno e não apenas num sentido psicológico, comparativo. Essa tese é sustentada face às objeções que apelam ao desinteresse do juízo de gosto e ao caráter psicológico da liberdade da imaginação.

Na primeira parte, considera-se o que é o juízo de gosto e como ele se produz. Na segunda, analisa-se a liberdade do jogo livre da imaginação com o entendimento. Na terceira, investigam-se os deveres da imaginação

\footnotetext{
${ }^{1}$ Sobre referências bibliográficas e traduções: As citações de textos de Kant são todas extraídas da edição de suas obras completas pela Academia das Ciências Alemã: KANT, I., Kant's gesammelteSchriften, herausgegeben von der Königlich Preussischen (Deutschen) Akademie der Wissenschaften, Berlin: Georg Reimer Verlag / Walter de Gruyter, 1907... A referência a essa edição é abreviada por 'Ak. $x$ : $s$ ', onde ' $x$ ' indica o número do volume e ' $\mathrm{s}$ ' as páginas.

A Kritik der Urteilskraft (Crítica da Faculdade do J uízo), obra mais citada, é abreviada como 'K. Ur.'.

Faremos referência à edição B (2ª edição) dessa Crítica indicando-a por 'B' seguido do número das páginas, e, em seguida, à da Academia: (Kant, I., K. Ur., B..., Ak. 5: ...). Utilizou-se, com uma certa liberdade, a tradução portuguesa da Crítica da Faculdade do J uízo (KANT, I., Crítica da Faculdade do J uízo, trad. Valério Rohden e Antônio Marques, Rio de J aneiro, Forense Universitária, 1993). Quanto ao termo 'Einbildungskraft', que Rohden e Marques traduzem geralmente por 'faculdade da imaginação', optou-se por traduzi-lo mais concisamente por 'imaginação'.

$\mathrm{O}$ autor traduziu o trecho da Preleção sobre Metafísica (KANT, I., Vorlesungen über Metaphysik, Ak. 28.2,1, (Vorlesungen 5, 2/1 - Metaphysik K3, Auszug Schlapp): 837) citado na nota 18.
} 
e do entendimento no ajuizamento de gosto. Finalmente, consideram-se algumas objeções à interpretação aqui apresentada.

I - O juízo de gosto é uma modalidade do juízo reflexivo estético e nele se atribuem a um objeto empírico os predicados 'belo' ou 'feio'. A faculdade do juízo é a faculdade de subsumir o particular sob o universal; se o universal é dado, cabendo buscar o particular a subsumir sob ele, tem-se o juízo determinante; se o particular é dado, cabendo procurar o universal sob o qual ele possa subsumir-se, tem-se o juízo reflexivo. ${ }^{2} \mathrm{~A}$ faculdade de juízo reflexiva tem um princípio a priori, originário dela mesma, o da conformidade a fins da forma da natureza na multiplicidade de suas leis empíricas particulares, ou, simplesmente, o da finalidade formal da natureza. 'Fim' significa aqui o conceito de um objeto, na medida em que é também o fundamento da efetivação desse objeto. Tal princípio é subjetivo apenas, pois não se funda nos conceitos puros do entendimento, que fundam a validade objetiva dos princípios puros da faculdade de juízo transcendental, que é determinante. Ele também é um princípio transcendental, enquanto condição universal apenas sob a qual as coisas podem se tornar objetos do conhecimento em geral. ${ }^{3}$ Assim o conhecimento empírico da natureza na multiplicidade de suas formas e leis empíricas particulares e a sistematização do mesmo têm como condição de possibilidade a atuação da faculdade de juízo reflexiva segundo esse princípio. Tal sistematização do conhecimento empírico da natureza parte de conceitos empíricos (fins) que fundamentam a efetivação do sistema; daí se considerar a conformidade a fins da forma da natureza na multiplicidade de suas leis particulares uma finalidade mediante fins. Não há aqui uma redundância, pois, ao conceber o juízo reflexivo estético, Kant entende a beleza como conformidade a fins sem fim, isto é, sem conceito determinado que funde a reflexão. ${ }^{4}$

Antes de considerar especificamente o juízo de gosto, vale notar que, segundo Kant, a realização de qualquer intenção gera um sentimento de prazer; assim, tomando-se como fim a sistematização do conhecimento empírico da natureza na multiplicidade de suas leis particulares, a realização do mesmo desperta um prazer correspondente. Há, porém, algum sentimento de prazer não engendrado pela realização de uma intenção, ou de um fim? Kant parece admitir um tal prazer ao fundá-lo num acordo não intencional de faculdades, resultante de um exercício sui generis de suas atividades. Embora supostamente não intencional, não fundado num fim, esse acordo gera um sentimento de prazer sobre o qual se funda a atribuição a um objeto do predicado 'belo', ou, o que é o mesmo, 'confor-

\footnotetext{
${ }^{2}$ Cf. KANT, I., K.Ur., B XXV-XVI, Ak. 5: 178-180.

${ }^{3}$ Cf. KANT, I., K.Ur., B XXIX, XXXIV, Ak. 5: 181, 184.

${ }^{4}$ Cf. KANT, I., K. Ur., B 33-35, Ak. 5: 220-221.
} 
me a fins sem fim'. Mas, que ligação há entre o conceito de conformidade a fins sem fim e este sentimento de prazer, sobre o qual ele se fundaria? ${ }^{5}$

Ora, segundo Kant, os sentimentos de prazer ou de dor representam a relação entre a representação de um objeto e o sujeito e não a relação entre esta representação e o próprio objeto, de modo que o prazer ou a dor não têm nenhuma validade objetiva, não se prestando em nada ao conhecimento de um objeto, mas possuem uma natureza estritamente subjetiva. $O$ princípio da finalidade formal da natureza, fundado sobre o conceito de conformidade a fins, é um princípio estritamente subjetivo, não possuindo a validade objetiva dos princípios puros da faculdade de juízo determinante. Embora seja a priori, o princípio da finalidade formal da natureza não é objetivo, pois o conceito da conformidade a fins, sobre o qual se funda, não é um conceito puro do entendimento, não tendo, portanto, validade objetiva. O caráter estritamente subjetivo tanto dos sentimentos de prazer ou dor quanto do conceito de conformidade a fins é o que sustenta a ligação entre eles, justificando, de certo modo, a atribuição de conformidade a fins sem fim - beleza - a um objeto cuja representação enseje o acordo não intencional, mas gerador de prazer, entre faculdades envolvidas no ajuizamento reflexivo estético de gosto sobre esse objeto. ${ }^{6}$

Como se produz o juízo de gosto? Observe-se, primeiramente, que, como não se trata de um juízo de conhecimento, com validade objetiva, ele não consiste na aplicação dos conceitos puros do entendimento, mediante os esquemas transcendentais da imaginação e segundo os princípios da faculdade de juízo transcendental, que é determinante, às intuições empíricas dos objetos. O juízo de gosto resulta da atividade da faculdade de juízo reflexiva, quando não fundada em representações puras - conceitos puros, esquemas transcendentais e princípios puros da faculdade do juízo determinante - nem tampouco em conceitos empíricos, o que distingue o juízo de gosto do juízo reflexivo cognitivo, que busca a sistematização do conhecimento empírico da natureza. Para haver o juízo de gosto o objeto tem de ser representado não como objeto de conhecimento nem como objeto da vontade, pois não se trata de produzir o seu conceito nem de realizar a sua existência. ${ }^{7}$ De que se trata, então?

Para haver um juízo de gosto, o ponto de partida é a percepção de um objeto singular, por exemplo, esta rosa. Parte-se, pois, de uma simples intuição empírica, sem qualquer conceito, puro ou empírico, pois não se trata de conhecer o objeto. Ora, se a imaginação (aqui entendida como faculdade das intuições, especialmente das intuições a priori, e ao mesmo tempo como faculdade das sínteses, não segundo as regras empíricas da

${ }^{5}$ Cf. KANT, I., K. Ur., B XXXIX, XLIV, XLV, Ak. 5: 187, 189, 190.

${ }^{6}$ Cf. KANT, I., K. Ur., B XLIII-XLIV, Ak. 5: 189-190.

${ }^{7}$ Cf. KANT, I., K. Ur., B XXVIII, 5-7, Ak. 5: 180-181, 204-205. 
imaginação reprodutiva, tampouco segundo os esquemas transcendentais), enquanto imaginação produtiva, for capaz de apreender/ produzir a pura forma do objeto percebido, dissociada de toda a matéria da sensação, então ela terá sido capaz de representar um universal muito peculiar. Este universal não é um conceito, pois o juízo de gosto não se funda em conceito, puro ou empírico, nem produz qualquer conceito, visto não ser um juízo de conhecimento; tampouco é uma simples intuição pura, meramente formal, como o espaço ou o tempo, pois se trata da forma de um objeto singular percebido. Esta forma tampouco é um esquema transcendental, fundado num conceito puro, que regula a imaginação para a aplicação desses conceitos a intuições, visando ao conhecimento. Finalmente, também não é uma imagem, pois esta contém uma matéria de percepção; já a forma apreendida em nada pode depender da matéria da sensação, para que fique assegurada a universalidade do juízo de gosto. ${ }^{8}$ Talvez seja lícito entendêla como um universal subjetivo: universal enquanto simples forma, dissociada de toda matéria (essa universalidade a torna, de certo modo, semelhante ao conceito); subjetivo, porquanto não possui a validade objetiva requerida para o conhecimento do objeto. ${ }^{9}$ Essa conjugação de universalidade e subjetividade confere à simples forma do objeto, apreendida / produzida pela imaginação produtiva, validade para toda a gente, tal que todos podem e devem representá-la do mesmo modo. ${ }^{10}$

A apreensão/ produção da simples forma do objeto, sem relação dessa forma a algum conceito, portanto, sem relação dela ao objeto enquanto objeto de conhecimento (pois só a relação a um conceito confere validade objetiva a uma representação), estabelece uma relação dela com o sujeito, ipso facto com as faculdades deste. Se esta relação for de adequação, a ela se ligará um sentimento de prazer. Mas, esta adequação supõe um acordo do sujeito consigo mesmo, ou de suas faculdades entre si. As faculdades envolvidas neste acordo são a imaginação (enquanto faculdade das intuições, especialmente a priori) e o entendimento (enquanto faculdade dos conceitos), precisamente aquelas atuantes na faculdade de juízo reflexiva, porque nesta é a imaginação que representa o particular dado (intuição) e a busca do universal sob o qual ele possa subsumir-se culmina no conceito do entendimento. Assim, a atividade da imaginação, atuante na faculdade de juízo reflexiva, desperta a atividade desta. Quando a imaginação apreende/ produz a simples forma universal do objeto a partir de sua intuição

${ }^{8}$ Cf. KANT, I., K. Ur., B 34-35, XLV, Ak. 5: 220-221, 190.

${ }^{9} \mathrm{Cf}$. KANT, I., Vorlesungen über Metaphysik, Ak. 28. 2,1 (Vorlesungen 5, 2/1, Metaphysik K3, Auszug Schlapp): 837. Pedro Costa Rego também emprega a expressão 'universal subjetivo', significando, porém, mais propriamente, o princípio do juízo de gosto. (Cf. COSTA REGO, P., O Gosto e a Fundação Estética dos J uízos na 3a Crítica de Kant, in Studia Kantiana / Revista da Sociedade Kant Brasileira, vol. 3, № 1, novembro de 2001, p. 150)

${ }^{10}$ Cf. KANT, I., K. Ur., B 17-20, XLVI, Ak. 5: 221-213, 190-191. 
empírica singular, a faculdade de juízo reflexiva assim ativada toma este caso particular de apreensão do universal (forma apreendida) e o leva ao universal que consiste na relação universal da imaginação (que dá a intuição em geral) ao entendimento (que produz o conceito em geral sob o qual a intuição em geral é subsumida). Nos termos de Kant, a faculdade de juízo reflexiva compara a apreensão da forma do objeto com a sua própria capacidade de relacionar intuições com conceitos. ${ }^{11} \mathrm{~A}$ adequação da forma apreendida ao sujeito, ligada ao prazer, ocorrerá sob a condição do acordo das faculdades do sujeito, aqui envolvidas, entre si, a saber, o entendimento e a imaginação, postas em relação pela atividade da faculdade de juízo reflexiva. É este acordo entre a imaginação e o entendimento que gera o prazer ligado à representação da forma apreendida/ produzida do objeto. Ora, este acordo das faculdades atuantes na faculdade de juízo reflexiva só é possível pelo acordo desta consigo mesma, o que implica em sua conformidade ao seu próprio princípio, o da conformidade a fins da natureza. Se, portanto, a forma apreendida se relaciona ao sujeito apenas (pois não é um conceito com validade objetiva) e se o conceito de conformidade a fins da natureza tem validade apenas subjetiva (porquanto não é uma categoria), então esse conceito não objetivo pode ser predicado do objeto, não enquanto objeto de conhecimento, mas enquanto objeto cuja simples forma apre endida gera, mediante a reflexão sobre esta apreensão, o sentimento de prazer, ou seja, enquanto objeto do gosto. A tribuir a esse objeto o predicado 'conforme a fins' é o mesmo que atribuir-Ihe o predicado 'belo'.

Cabe compreender melhor as condições que possibilitam o juízo de gosto. Este é possibilitado por um uso não cognitivo (não lógico), mas estético, da faculdade de juízo reflexiva, que não se funda em nenhum conceito de objeto. N esta medida, a imaginação, atuante na faculdade do juízo reflexiva, não opera sob nenhum conceito enquanto regra de síntese, mas exerce sua atividade de modo não regulado, ao buscar apreender / produzir a simples forma do objeto percebido. Kant chama esta atividade sem regra, da imaginação, de 'livre'. Haveria aqui um uso espúrio do conceito de liberdade? Talvez a resposta seja negativa, à luz de uma análise mais aprofundada. ${ }^{12}$

${ }^{11}$ Cf. KANT, I., K. Ur., B XLIV-XLV, Ak. 5: 189-190.

12 É pouco plausível que Kant tenha empregado, numa mesma passagem da Crítica da Faculdade do J uízo, o mesmo termo 'liberdade' com dois sentidos diferentes, conforme se refira à vontade ou à imaginação, sem nenhuma explicitação adequada da suposta diferença de sentido: "A liberdade da faculdade da imaginação (portanto, da sensibilidade de nossa faculdade) é representada no ajuizamento do belo como concordante com a legalidade do entendimento (no juízo moral a liberdade da vontade é pensada como concordância da vontade consigo própria segundo leis universais da razão)." (KANT, I., K. Ur., B 259, Ak. 5: 198). 
II - A imaginação em sua atividade não regulada não está submetida a nenhuma regra particular ou lei universal do entendimento, o que não implica numa necessária oposição de sua atividade às regras ou leis do entendimento. Tanto é assim que é até possível um acordo não intencional entre a imaginação e o entendimento, no ajuizamento de gosto. É certo, porém, que, no ajuizamento de gosto, o entendimento não é legislador para a imaginação. Levando isso em conta, podem-se interpretar formulações kantianas como 'o jogo livre da imaginação com o entendimento', 'a conformidade a leis sem lei', 'o acordo da liberdade da imaginação com a legalidade do entendimento'. ${ }^{13}$

Se, na compreensão da liberdade, for enfatizado o seu aspecto de não regulação, é possível admitir a liberdade da imaginação na sua atividade sem regra de apreensão da simples forma do objeto percebido, bem como a liberdade do próprio entendimento, ao eximir-se de legislar para a imaginação no ajuizamento de gosto, agindo de modo não regulado, isto é, indiferente às regras objetivas de seu uso cognitivo, lógico. Assim, imaginação e entendimento, no exercício das respectivas liberdades, participariam de um 'jogo livre'. ${ }^{14}$

E quanto à 'conformidade a leis sem lei' da imaginação, que, no ajuizamento de gosto, chega ao acordo com o entendimento? Ora, a imaginação, sem tomar como regra nenhum conceito, portanto sem lei, apreende/ produz a simples forma do objeto percebido como universal subjetivo (sem validade objetiva) e, mediante a reflexão sobre essa apreensão, chega ao acordo com o entendimento, isto é, chega à conformi dade a leis. Pois, o entendimento, enquanto faculdade dos conceitos puros, é a faculdade das leis, do universal objetivo, com o qual se conforma o universal subjetivo produzido pela imaginação: conformam-se um ao outro enquanto são, ambos, válidos para toda a gente, para todos os sujeitos. Há, pois, uma conformidade a leis sem lei, sem regras e, neste sentido, livre, da imaginação.

Por último, considere-se o 'acordo da liberdade da imaginação com a legalidade do entendimento'. A imaginação produtiva, agindo sem um con-

\footnotetext{
${ }^{13}$ Cf. KANT, I., K. Ur., B 259, 199, 28, 32, 37, 47, 71, 69, Ak. 5: 198, 163, 61-62, 64, 68, 74, 87-88, 86.

${ }^{14}$ Dieter Henrich também enfatiza a liberdade do próprio jogo das faculdades cognitivas: “Kant inclina-se a chamar também o próprio jogo (e não apenas a performance da imaginação) de 'livre' e (...) ele poderia muito bem descrever o inteiro estado do ânimo dentro do jogo como um estado de liberdade. Nosso conhecimento depende inescapavelmente da coerção mútua: nosso entendimento é restrito no seu uso ao que é dado na intuição e nossa imaginação tem que servir sob os princípios de unidade do entendimento (...) podemos dizer que somente na situação estética (...) a coerção cessa, e um acordo sem coerção prevalece. Não é de surpreender que um tal estado seja experimentado com prazer." (HENRICH, D., Aesthetic J udgment and the Moral I mage of the World, Stanford: Stanford University Press, 1992, pp. 52, 53).
} 
ceito como regra, exerce sua espontaneidade sintética, sem sujeitar-se à coação dos conceitos puros do entendimento e dos esquemas transcendentais para a aplicação desses conceitos às intuições: esta espontaneidade não coagida parece merecer a denominação de 'liberdade'. O acordo dessa liberdade não é propriamente com a legislação do entendimento, pois esta incluiria a coação sobre a imaginação, impondo-lhe o atuar em conformidade com os conceitos puros e os esquemas transcendentais; mas, é propriamente com a legali dade do entendimento que a liberdade da imaginação entra em acordo. Entenda-se tal legalidade como a forma da universalidade dos conceitos puros e princípios a priori do entendimento, pois essa éa forma da lei em geral. ${ }^{15} \mathrm{~A}$ liberdade que engendra o universal subjetivo pode entrar em acordo com a legalidade do universal objetivo.

A té agora, a liberdade foi entendida ou como a espontaneidade de uma atividade sem regras (liberdade da imaginação) ou como a omissão de sua legislação (liberdade do entendimento). O jogo livre da imaginação e do entendimento, fundamento do ajuizamento de gosto, consistiria no exerć́cio de suas respectivas liberdades. Mas, aqui parece afirmar-se a idéia de um jogo completamente isento de regras, exercício aleatório, mera casualidade, o que parece em desacordo com o conceito kantiano de liberdade, enquanto propriedade de uma espécie de causalidade e, como tal, necessariamente sujeita a uma lei. Cumpre, pois, examinar se há al guma lei, ou princípio, segundo o qual tal jogo livre se exerça.

Segundo Kant, a satisfação universalmente válida, fundada na harmonia da liberdade da imaginação com a legalidade do entendimento, produzida pelo livre jogo dessas faculdades no ajuizamento de gosto, é uma complacência segundo uma lei universal. ${ }^{16}$ Tal complacência é o efeito universal e necessário de uma causalidade que consiste justamente no livre jogo da imaginação com o entendimento, e que, como causalidade, tem de operar segundo uma lei a priori.

Note-se, ademais, que a faculdade de juízo reflexiva tem um princípio a priori, originário dela mesma e de natureza simplesmente subjetiva, o da conformidade a fins da natureza. Este princípio éo da 'heautonomia', pois, neste caso, a faculdade de juízo reflexiva dá o princípio apenas para si mesma. Mas, segundo Kant, as máximas da faculdade de juízo reflexiva,

${ }^{15}$ Cf., KANT, I., Grundlegung zur Metaphysik der Sitten, Ak. 4: 420-421, 436.

${ }^{16} \mathrm{Na}$ Antropologia de um ponto de vista pragmático lemos: “Ora, a satisfação que pode ser considerada como válida não somente para o sujeito que a sente, mas também para todos os outros, isto é, como universalmente válida, porque ela tem de conter uma necessidade (a dessa satisfação), portanto um princípio a priori, é uma satisfação que se toma pela coincidência do prazer do sujeito com o sentimento de todos os outros, segundo uma lei universal, a qual tem de provir do princípio de legislação universal do sujeito que sente [tal satisfação], conseqüentemente tem de provir da razão (...)". (KANT, I., Anthropologie in pragmatischer Hinsicht, Ak. 7: 244). 
como a de que 'a natureza não dá saltos', fundadas sobre esse princípio, são máximas de como se deve julgar reflexivamente e não de como efetivamente se julga. ${ }^{17}$ Portanto, parece lícito admitir que o princípio da faculdade de juízo reflexiva é o princípio a priori de como ela deve julgar, tendo, pois, a forma do dever incondicional.

Considere-se também que o juízo de gosto é uma das modalidades do juízo reflexivo estético (a outra é o juízo do sublime), que, por sua vez, é uma das modalidades do juízo reflexivo (a outra é o juízo reflexivo teleológico); por conseguinte, se o juízo reflexivo se produz segundo o princípio a priori da faculdade de juízo reflexiva - princípio (da heautonomia) com a forma do dever -, então o juízo de gosto terá de se produzir segundo o mesmo princípio com a forma do dever.

Ora, o entendimento e a imaginação, em livre jogo no ajuizamento de gosto, são as faculdades cognitivas atuantes na faculdade de juízo reflexi-

\begin{abstract}
${ }^{17}$ Aqui é importante reproduzir passagens do texto de Kant, para sustentar que o princípio transcendental da faculdade do juízo, o da conformidade a fins formal da natureza, tem a forma do dever: "Mas se pode facilmente concluir da natureza da faculdade do juízo (cujo uso correto (richtiger Gebrauch) é tão necessário e universalmente requerido que por isso sob o nome de são entendimento não se tem em mente nenhuma outra faculdade senão precisamente essa), que comporta grandes dificuldades descobrir um princípio peculiar dela(...)" (KANT, I., K. Ur., B VII, Ak. 5: 169). "Porém, se só o particular for dado, para o qual ela deve encontrar (finden soll) o universal, então a faculdade do juízo é simplesmente reflexiva." (KANT, I., K. Ur., B XXVI, AK. 5: 179). "A faculdade de juízo reflexiva, que tem a obrigação (Obliegenheit) de elevar-se do particular na natureza ao universal, necessita por isso de um princípio que ela não pode retirar da experiência; (...) só a faculdade de juízo reflexiva pode dar a si mesma um tal princípio como lei (...)" (KANT, I., K. Ur., B XXVI-XXVII, Ak. 5: 180). "O fato de o conceito de uma conformidade a fins da natureza pertencer a princípios transcendentais é bastante compreensível a partir das máximas da faculdade do juízo que são postas a priori como fundamento da investigação da natureza (...). Mas, se tentarmos a via da psicologia para darmos a origem destes princípios [(máximas)], contrariamos completamente seu sentido. É que eles não dizem aquilo que acontece, isto é, segundo que regras é que as nossas faculdades de conhecimento estimulam efetivamente o seu jogo e como é que se julga, mas sim como é que deve ser julgado (wie geurteilt werden soll)." (KANT, I., K. Ur., B XXX-XXXI, AK. 5: 26-27.) A seguinte passagem também estabelece o caráter normativo desse princípio: "Na verdade é uma ordem (Geheiss) da nossa faculdade do juízo proceder segundo o princípio da adequação da natureza à nossa faculdade de conhecimento, tão longe quanto for possível (...)" (KANT, I., K. Ur., B XLI, Ak. 5: 32). Pode-se, ademais, admitir que o ajuizamento de gosto tem um princípio com a forma do dever, se for levado em conta que o próprio juízo de gosto, bem como o prazer correspondente, deve ser exigido de cada um: “Todavia o juízo de gosto exige somente ser válido para toda gente, tal como todos os outros juízos empíricos (..) O que é estranho e invulgar é somente o fato de ele não ser um conceito empírico, mas sim um sentimento de prazer (por conseguinte nenhum conceito), o qual, todavia, mediante o juízo de gosto, deve ser exigido (zugemuthet werden soll) de cada um." (KANT, I., K. Ur., B XLVI, AK. 5: 34-35.)
\end{abstract}

Roger Scruton também reconhece que o juízo estético, em Kant, contém um 'dever': "O juízo estético contém um 'dever' (ought): outros devem (ought) sentir como eu, e, na medida em que não o fazem, ou eles estão errados ou eu estou." (SCRUTON, R., Kant, Oxford: Oxford University Press, 1982, p. 82). 
va, de modo que, se esta atua segundo um princípio com a forma do dever incondicional, parece válido concluir que o entendimento e a imaginação estariam de algum modo sujeitos a deveres incondicionais.

Podese objetar que a faculdade do juízo é uma faculdade distinta da imaginação e do entendimento, não consistindo num mero somatório destes; assim, o fato de a faculdade do juízo estar submetida a um princípio com a forma do dever não implicaria em que a imaginação e o entendimento também o estivessem. Sem dúvida, a questão da relação da faculdade do juízo com a imaginação e o entendimento, mereceria uma investigação especial, que, todavia, não se pode empreender aqui. Mas, cabem al gumas breves considerações a respeito. Entendendo-se em geral a faculdade do juízo como a de subsumir o particular sob o universal, a imaginação (que inclui a sensibilidade) como a faculdade de intuir e receber a representação do particular bem como de realizar sínteses, e o entendimento como a faculdade de produzir conceitos, podem-se reconhecer semelhanças de funções entre elas. ${ }^{18}$ A subsunção de uma representação (particular) sob outra (universal), operada pela faculdade do juízo, não deixa de ser uma síntese, ligando essas representações desconexas; ora, as sínteses competem à imaginação. Por sua vez, a intuição empírica do múltiplo e a síntese que o leva à unidade da forma apreendida, operada pela imaginação produtora, é o encontro da relação de subsunção do particular (intuído) sob o universal (apreendido), o que é da alçada da faculdade do juízo. Finalmente, a produção de conceitos, ao menos os empíricos, consiste na síntese dos particulares na unidade de uma representação comum (por comparação, reflexão e abstração), isto é, na subsunção dos particulares sob o universal produzido, o que parece, de certo modo, caber também à faculdade do juízo e à imaginação. ${ }^{19}$ Se for assim, podem-se, ao menos preliminarmente, admitir semelhanças de funções dessas 'distintas' faculdades. Portanto, não seria de admirar que, estando a faculdade de juízo reflexiva submetida a um princípio com a forma do dever, também a imaginação e o entendimento se submetam a deveres.

Mas, como poderia a imaginação estar sujeita a al gum dever no ajuizamento de gosto, se a síntese, operada por ela (que apreende / produz a forma do objeto ao unificar o múltiplo percebido), não se produz segundo nenhum conceito, portanto, ao que parece, tampouco segundo o conceito de dever? Ora, convém observar que, a rigor, tal síntese não se realiza segundo um conceito determinado de objeto, puro ou empírico, que se possa referir a alguma intuição, mas, ainda assim, realiza-se segundo um conceito indeterminado, o do supra-sensível, conforme se pode verificar na solução

${ }^{18}$ Cf. KANT, I., K. Ur., B XXV-XXVI, 28, 65, 69, Ak. 5: 179-180, 217, 238, 240-241; Logik, Ak. 9: 94-95.

${ }^{19}$ Cf. KANT, I., Logik, Ak. 9: 94-95. 
kantiana da antinomia do gosto. É o conceito do supra-sensível, chave da solução das antinomias da razão, teórica, prática ou do gosto, que, no caso desta última, tomado enquanto princípio da conformidade a fins subjetiva da natureza para nossa facul dade de conhecimento, possibilita o ajuizamento de gosto e, ipso facto, a síntese da apreensão / produção da forma do objeto. ${ }^{20}$ Ora, esse conceito indeterminado (do supra-sensível), enquanto princípio subjetivo da faculdade de juízo reflexiva, contém o conceito do dever, pois este princípio tem a forma do dever; portanto, o conceito do dever, contido no do supra-sensível, possi bilita a síntese da imaginação no ajuizamento do gosto, sem descaracterizá-la. Todavia, é sem dúvida estranho que um conceito indeterminado (o do supra-sensível) contenha em si o conceito determinado do dever. Mas, não há dúvida de que o próprio Kant entende o conceito do supra-sensível, na solução da antinomia do gosto, como o princípio da conformidade a fins subjetiva da natureza para a nossa faculdade de conhecimento. E este princípio teria a forma do dever.

III - Quais poderiam ser os deveres incondicionais da imaginação e do entendimento no ajuizamento de gosto? O dever da imaginação seria o de apreender/ produzir a simples forma, dissociada de toda a matéria, do objeto percebido, e entrar em acordo com a legalidade do entendimento ou, pelo menos, não entrar em desacordo com esta; é claro que a imaginação pode fazêlo ou não, mas deve fazêlo, possi bilitando o juízo do gosto. Se a forma não for apreendida dissociada de toda matéria, o universal subjetivo não será produzido nem poderá haver o acordo do livre jogo da imaginação com a legalidade do entendimento, conseqüentemente a validade do juízo de gosto para toda a gente não será lograda. ${ }^{21}$ Ademais, o

${ }^{20}$ Cf. KANT, I., K. Ur., B 237, 238, Ak. 5: 340, 341.

${ }^{21}$ Esta interpretação parece estar de acordo com a seguinte passagem de uma Preleção sobre Metafísica, especialmente os itens ' $b$ ', 'c' e 'd', que fornece uma formulação concisa e interessante da Doutrina da Beleza kantiana:

“Belo, no ajuizamento estético, é somente aquilo que, sem nenhum interesse na existência mesma do objeto, apraz simplesmente na intuição do mesmo, aliás, na forma do mesmo, pois aqui atua um livre jogo da imaginação em acordo com a legalidade do entendimento. Daqui resulta, portanto:

a) Que tudo que deve ser belo tenha de ao menos ter semel hança com os conceitos ou com as leis do entendimento. Todavia, não é de modo algum necessário a consciência das regras ou destas leis do gosto, mas somente é necessário sua existência no sujeito, tanto quanto possa servir para o apoio e a orientação da imaginação. Daí que esses conceitos do entendimento possam existir também não em sua [(da imaginação)] determinação;

b) Que a imaginação se ocupe somente com a forma do objeto e não com sua existência corpórea, portanto, que ela não seja desaprovada nos limites e na falta do objeto, mas mantenha em si um vôo ilimitado, para produzir a forma; que com isso, porém, ela não siga somente suas leis e extravague além da conformidade com o objeto, mas apenas produza, para o entendimento, uma multiplicidade no objeto para o todo;

c) O entendimento, a cada vez, chama-a [(a imaginação)] novamente à ordem, contém-na em limites, segundo o que, então; 
cumprimento do dever da imaginação, de apreender / produzir a simples forma do objeto percebido, produz a conformidade do universal subjetivo (forma apreendida) com a universalidade dos conceitos puros (universais objetivos), portanto, com a legalidade do entendimento. Se a imaginação extravagar (extravagieren), sem produzir a forma universal, a não-conformidade com a legalidade do entendimento lhe adverte a retomar a produção da forma, como é seu dever. É como se o entendimento a chamasse à ordem, auxiliando-a a produzir a forma. Aliás, parece que o desprazer resultante daquela não-conformidade incentiva a imaginação a harmonizar-se com a legalidade do entendimento. No ajuizamento do gosto, 0 dever e o prazer no belo estariam em sintonia.

Pois bem, se à espontaneidade sem regras da imaginação for associada sua sujeição a um dever incondicional, parece que a liberdade, num sentido autêntico, deveria ser atribuída à imaginação. ${ }^{22}$ Mas, uma dificuldade se

d) Ambas as faculdades (Kräfte) se apóiam reciprocamente, fazem um livre jogo e se ocupam assim com complacência." (KANT, I., Vorlesungen über Metaphysik, Ak. 28.2,1, (Vorlesungen 5, 2/1 - Metaphysik K3, Auszug Schlapp): 837).

Que o entendimento, embora sem coagir a imaginação (sem submetêla a uma regra), contenha a liberdade da imaginação dentro de certos limites; que, ao menos, esta liberdade deva não estar em desacordo com o entendimento, é o que nos ensina também a seguinte passagem: "Mas, onde somente deve ser entretido um jogo livre das faculdades de representação (contudo sob a condição de que o entendimento não sofra aí nenhuma afronta) (...) a conformidade a regras, que se anuncia como coerção, é tanto quanto possível evitada." (KANT, I., K. Ur., B 71, Ak. 5: 87-88). Esta outra passagem, relativa à questão do gênio e da arte bela, sustenta, nessa mesma linha, que "(...) a faculdade do juízo, que sobre assuntos da arte bela profere a sentença a partir de princípios próprios, permitirá prejudicar antes a liberdade e a riqueza da faculdade da imaginação do que o entendimento." (KANT, I., K. Ur., B 203, Ak. 5: 165).

Contudo, Dieter Henrich, ao comentar o trecho citado daquela Preleção sobre Metafísica, afirma que o próprio Kant teria feito uma descrição inadequada do jogo livre: "Kant atribui aqui ao poder do entendimento a função de, num certo sentido, curvar a imaginação. Em seu jogo livre, a imaginação tende a tornar-se extravagante. Se isto acontece, o entendimento a chama à ordem. Apenas assim o jogo harmonioso é assegurado. Eu sugiro que se tome isso como uma descrição de algum modo desencaminhada do jogo mesmo. Ela confunde um componente verdadeiramente imaginário do jogo com sua constituição total." (HENRICH, D., Aesthetic J udgment and the Moral Image of the World, Stanford: Stanford University Press, 1992, pp. 52-53).

22 Paul Guyer atribui autonomia, isto é, liberdade no sentido positivo, ao juízo estético de gosto, sendo, ao que parece, cabível atribuí-la à relação do entendimento com a imaginação: "(...) a resposta estética e o juízo moral são, ambos, autônomos, juízos em que o ânimo não é determinado por conexões causais contingentes e meramente naturais." (GUYER, P., Kant and the Claims of Taste, Cambridge: Cambridge University Press, 1979, p. 380). Contudo, pode-se questionar se a interpretação de Guyer é inteiramente consistente, pois, segundo ele, apenas os juízos morais empregam o conceito de legislação universal: "Os juízos estéticos e morais são estruturalmente análogos (...). Porém, eles diferem em dois pontos: juízos estéticos não empregam nenhum conceito de objetos (e por essa razão, talvez, não podem estabelecer nenhum interesse), enquanto que os juízos morais, obviamente, têm que empregar o conceito de legislação universal para poder estimar as formas das máximas: e somente os juízos morais podem produzir um interesse, sem pressupô-lo." (GUYER, P., op. cit. 368). 
apresenta: como conciliar tal isenção de regras com a sujeição a uma regra deôntica universal?

Aqui, a comparação da liberdade da imaginação produtiva com a do livrearbítrio pode ser elucidativa. O livre-arbítrio (freie Willkür) está sob a legislação da vontade (Wille) stricto sensu, que produz uma lei - a lei moral, com a fórmula do Imperativo Categórico - e um móbil, a Idéia do dever. Como o livre-arbítrio é um poder de um ser racional, que como tal age segundo princípios, o livre-arbítrio age segundo princípios subjetivos - as máximas - enquanto que a lei, princípio objetivo, Ihe é ditada pela vontade. Ora, as máximas são regras subjetivas, adotadas livremente pelo livre-arbítrio, que é, portanto, auto-regulador. ${ }^{23}$ Mas, haveria a possibilidade de algum ato do livre-arbítrio não regulado por qualquer máxima? Parece que sim, em se tratando do ato de adoção da máxima fundamental, conforme se depreende da interpretação da doutrina do mal radical. ${ }^{24} \mathrm{~A}$ máxima fundamental, não derivada de nenhuma outra máxima, tem de ser adotada livremente pelo arbítrio agindo segundo a lei moral, mas não regulado por qualquer máxima; portanto, esta adoção livre é um ato do livre-arbítrio não regulado, um exercício de sua liberdade. Ora, uma liberdade em certa medida congênere é que se atribui aqui à imaginação, em sua atividade sob a obrigação incondicional de apreensão da simples forma do objeto, exercida sem fundamento em qualquer conceito de objeto como regra. Assim, se a solução proposta para a questão do ato fundamental do livre-arbítrio for válida, talvez deva estender-se à questão da liberdade da imaginação no ajuizamento de gosto.

E quanto ao dever do entendimento no ajuizamento de gosto? Parece que ele consistiria em não coagir a imaginação a operar segundo os seus conceitos puros e esquemas transcendentais, pois isto a impediria de apreender / produzir a simples forma do objeto percebido. Mas, não haveria aqui um inaceitável conflito de deveres do entendimento? Isto é, de um lado, o dever de coagir a imaginação a operar de acordo com os seus princípios a priori, para produzir juízos de experiência, de outro lado, o dever de não exercer a mesma coação, para possibilitar o ajuizamento de gosto? Talvez não haja incompatibilidade entre esses deveres mesmos, mas haveria apenas entre seus cumprimentos, se exigidos como simultâneos. Ademais, esses deveres aparentemente conflitantes poderiam ser vistos como, de certo modo, condicionados pelo uso do entendimento (aliás, exigindo da imaginação diferentes contrapartidas): se o entendimento quer o ajuizamento de gosto, deve não coagir a imaginação; se ele quer o ajuizamento cognitivo, deve então coagi-la. Com isso, talvez se dissolva o aparente conflito.

${ }^{23}$ Cf. KANT, I., Metaphysik der Sitten, Ak. 6: 226.

${ }^{24}$ Cf. KANT, I., Metaphysik der Sitten, Ak. 6: 21-22, 39-40. 
Um reforço à idéia de que, no ajuizamento de gosto, o entendimento e a imaginação produtiva estariam sujeitos ao dever, tendo a liberdade num sentido genuíno, é o fato de Kant conceber a cultura das faculdades, ou poderes naturais, para os mais diversos fins, como um dever do homem para consigo mesmo. Entre esses poderes se encontra a imaginação, sobre a qual repousa o gosto, cuja importância para a vida civilizada é destacada. ${ }^{25}$ Mas, como seria possível a cultura da imaginação, sobre a qual se funda a do gosto, se, no ajuizamento de gosto, a imaginação não se submete a nenhuma regra? Seria possível fomentá-la por um procedimento aparentemente aleatório? Talvez a possibilidade dessa cultura se deva, antes, ao fato de que a imaginação está sob a obrigação auto-imposta de apreender a simples forma do objeto percebido e age segundo esse princípio, podendo, enfim, se cultivar.

IV - Se, por um lado, esta interpretação parece se coadunar com a exigência de universalidade e necessidade do juízo de gosto, como juízo que se deve esperar de toda a gente, devido à universalidade da forma apreendida pela imaginação produtiva; se, ademais, parece em sintonia com a concepção kantiana da beleza como conformidade a fins sem fim, isto é, sem conceito; por outro lado, ela parece esbarrar no caráter desinteressado da complacência sobre a qual se funda o juízo de gosto. ${ }^{26}$ Isto porque, de acordo com esta interpretação, o ajuizamento de gosto se faz segundo um princípio a priori com a forma do dever - o da conformidade a fins formal da natureza; ora, atribuir a forma do dever a este princípio não implica em comprometêlo com um interesse, impossibilitando a atribuição de um caráter desinteressado aos juízos de gosto produzidos segundo esse princípio? O interesse é, para Kant, a complacência ligada à representação da existência do objeto. A complacência no agradável é ligada a interesse, porque este prazer é ligado à representação da existência do objeto que afeta nossos sentidos. A complacência no bom é também ligada a interesse, pois este prazer é ligado à representação da existência do objeto enquanto ação moral, realizada de acordo com o princípio prático supremo, o princípio do dever moral, e tendo como efeito a complacência despertada no sentimento moral. ${ }^{27} \mathrm{E}$ quanto à complacência no belo? Ela não seria também um efeito da faculdade de juízo reflexiva, agindo de modo não intencional, isto é, não fundada em um fim, ou conceito, mas ainda assim realizada segundo um princípio do dever-julgar? A obediência a esse princípio deôntico não visaria, como toda ação moral, à realização de algo? Enfim, a complacência no belo não estaria ligada à representação da exis-

${ }^{25}$ Cf. KANT, I., Metaphysik der Sitten, Ak. 6: 444, 445.

Philonenko também interpreta o cultivo do gosto, em Kant, como um dever. (PHILONENKO, A., L'Oeuvre de Kant, tome II, Paris: J.Vrin, 1981, p. 183)

${ }^{26}$ Cf. KANT, I., K. Ur., B 5-7, 16, Ak. 5: 48-50, 55.

${ }_{27}$ Cf. KANT, I., K. Ur., B 7-16, Ak. 5: 50-55. 
tência desse algo realizado? Tal complacência não seria, portanto, interessada? Talvez se evite essa conclusão, se for entendida mais precisamente a natureza desse algo que a faculdade de juízo reflexiva tem o dever de realizar, daí resultando a complacência no belo. Esse algo a realizar seria, primeiramente, a forma apreendida do objeto, não o objeto propriamente, enquanto fenômeno percebido, onde se associam forma e matéria; assim, a complacência seria ligada à representação não da existência do objeto, mas de sua forma apenas, com o qual o desinteresse estaria garantido. Em segundo lugar, esse al go a realizar seria também o acordo das faculdades da imaginação e do entendimento em seu jogo livre, uma condição do sujeito, a cuja representação liga-se a complacência no belo. Esta complacência não se liga, portanto, à representação da existência do objeto; por conta disso, também, ficaria assegurado o desinteresse do ajuizamento de gosto.

Embora o ajuizamento de gosto seja não intencional, porquanto aí a faculdade de juízo reflexiva não se funda em qualquer conceito, ou fim, como regra, há para ela, em certo sentido, um fim, cuja realização é um dever: a apreensão da simples forma e o livre acordo do entendimento com a imaginação, gerador da complacência no belo. Esta, resultante desse livre acordo, provém, de certo modo, da realização de uma intenção - a de realizar esse acordo devido. ${ }^{28}$

Uma possível e grave objeção a essa atribuição de liberdade num sentido absoluto à imaginação, no ajuizamento de gosto, éque se atrela a atividade da imaginação à condição temporal da percepção do objeto. Ora, uma atividade que se inicie no tempo não poderia ser considerada livre senão num sentido relativo, comparativo, psicológico, mas não num sentido ab-

${ }^{28}$ A realização dessa intenção, embora não seja pré-requisito para a disposição das faculdades cognitivas ao conhecimento em geral, condiciona essa disposição e contribui para ela: "O prazer que sentimos, como consciência do jogo vivificado de imaginação e entendimento, é consciência estética da possibilidade de que algo venha a ser conhecido, mesmo que nada venha a ser conhecido (...), consciência da Stimmung pré-objetiva das faculdades de conhecimento à medida que ela condiciona a possibilidade de um conhecimento em geral." (COSTA REGO, P., O Gosto e a Fundação Estética dos J uízos na 3a Crítica de Kant, in Studia Kantiana (Revista da Sociedade Kant Brasileira), vol. 3, no 1, novembro de 2001, p. 157). Cf. HENRICH, D., Aesthetic J udgment and the Moral I mage of the World, Stanford: Stanford University Press, 1992, p. 43. Para Paul Guyer também, o ajuizamento de gosto, embora seja não intencional, porquanto não se funda em nenhum conceito enquanto fim particular, realiza, por outro lado, um fim ou objetivo geral, a harmonia das faculdades cognitivas (a imaginação e o entendimento): "Conforme a interpretei, a harmonia entre a imaginação e o entendimento é a consecução, ou a realização, de um objetivo (...) esse estado produz e, como logo veremos, é somente manifesto em um sentimento de prazer. (...) o que temos aqui é uma descrição lúcida de um prazer produzido por uma unificação de um múltiplo, realizada sem nenhuma consciência de regras formuladas conceitualmente. A explicação do gozo da harmonia gira em torno do fato de que o objetivo cognitivo geral de apreender um múltiplo e uni-lo no ânimo foi realizado sem consciência de coerção por algum conceito." (GUYER, P., Kant and the Claims of Taste, Cambridge: Cambridge University Press, 1979, p. 93). 
soluto, prático ou transcendental, pois estaria submetida ao princípio da causalidade natural. ${ }^{29}$

Tal objeção poderia estender-se ao juízo em geral, inclusive ao determinante? Ora, em qualquer juízo empírico, seja o determinante, em que se parte do universal e se busca o particular a subsumir sob ele, seja o reflexivo, em que se parte do particular dado e se busca o universal sob o qual seja subsumido, parece haver um condicionamento temporal da atividade de julgar pelo particular, que é uma intuição ou um conceito dependentes da percepção, temporalmente condicionada, de um fenômeno. Mas, poder-seia atribuir a liberdade transcendental à faculdade de julgar nos seus usos teórico e prático, como o faz Kant na terceira seção da Fundamentação da M etafísica dos Costumes, se o juízo for entendido como uma atividade discursiva condicionada temporalmente, como tal supostamente dependente da causalidade segundo leis da natureza?

Voltando ao ajuizamento de gosto, dever-se-ia talvez pensar a atividade da imaginação (nesse ajuizamento), condicionada temporalmente, como uma simples manifestação, ou fenômeno, de uma livre atividade atemporal produtora de acordo entre faculdades, à maneira do ato atemporal do livre-arbítrio, de adoção da máxima fundamental, pensado por Kant? Mas, aqui, é imprudente se adentrar na escuridão...

Bibliografia:

COSTA REGO, P., O Gosto e a Fundação Estética dos Juízos na 3a Crítica de Kant, in Studia Kantiana ( Revista da Sociedade Kant Brasileira), vol. 3 no 1, novembro de 2001, pp. 141-159.

GUYER, P., Kant and the Claims of Taste, Cambridge: Cambridge University Press, 1979.

Kant and the Experience of Freedom, Cambridge: Cambridge University Press, 1993.

\footnotetext{
${ }^{29}$ Segundo Paul Guyer, há um elemento psicológico, ao mesmo tempo interessante e problemático, na concepção kantiana da harmonia das faculdades cognitivas, no ajuizamento de gosto. Pode-se admitir que tal elemento condicione a atividade da faculdade da imaginação nesse ajuizamento: “(...) o elemento psicológico que tem de ser atribuído ao conceito kantiano da harmonia das faculdades, embora crucial para muito do poder explanatório e interesse de sua teoria estética, tem-se também de reconhecer como pondo limites ao sucesso da dedução do juízo estético." (GUYER, P., Kant and the Claims of Taste, Cambridge: Cambridge University Press, 1979, p. 394). Roger Verneaux entende que a liberdade em questão no 'jogo da imaginação', no ajuizamento de gosto, é uma liberdade psicológica, empírica, relativa, não a liberdade num sentido transcendental ou prático, positivamente definida como autonomia. (Cf. VERNEAUX, R., Le Vocabulaire de Kant, Paris: Aubier Montaigne, 1973, p. 210).
} 
GERHARDT, V., HORSTMANN, R. P., SCHUMACHER, R. (Hrsg.) Kant und die Berliner Aufklärung - Akten des IX. Internationalen KantKongresses, Band 3, Berlin: Walter de Gruyter, 2001.

HENRICH, D., A esthetic Judgment and the M oral Image of the World / Studies in Kant, Stanford: Stanford University Press, 1992.

KANT, I., Kant's gesammelte Schriften, herausgegeben von der Königlich Preussischen (Deutschen) Akademie der Wissenschaften, Berlin: Georg Reimer Verlag / / Walter de Gruyter, 1907.

Crítica da Faculdade do Juízo, trad. Valério Rohden e Antônio Marques, Rio de Janeiro : Forense Universitária, 1993.

PHILONENKO, A., L'O euvre de Kant / La philosophie critique, tome II, Paris : J. Vrin, 1981.

SCRUTON, R., Kant, Oxford: Oxford University Press, 1982.

VERNEAUX, R., Le Vocabulaire de Kant, Paris: Aubier Montaigne, 1967.

ENDEREÇO DO AUTOR:

Rua Visconde de Pirajá, 175, Apto. 502

22410-001 Rio de Janeiro - RJ

e-mail: edgard@rdc.puc-rio.br 